\title{
Spaces of Social Action to Improve the Current Socioeconomic Situation of Venezuelan Immigrant Children in the Department of La Guajira
}

\author{
Emérita Sofía Muñoz Estrada ${ }^{\# 1}$, Mirian Muñoz Estrada ${ }^{\# 2}$, Katy Cecilia Herrera ${ }^{\# 3}$, \\ Lina Meza-Andrade ${ }^{\# 4}$, Javier Pinedo ${ }^{* 5}$ \\ \# University of Guajira, La Guajira, Colombia \\ 1 emunoz@unigajira.edu.co \\ 2 mrmunoz@unigajira.edu.co \\ ${ }^{3}$ katyherrera@unigajira.edu.co \\ ${ }^{4}$ linameza@unigajira.edu.co \\ * Faculty of Engineering, University of Cartagena, Colombia \\ 5 javierpined@hotmail.com
}

\begin{abstract}
The purpose of this research is to implement spaces for social action to improve the current socioeconomic situation of Venezuelan immigrant children in the Department of La Guajira. It became necessary to investigate how a large number of immigrant children live in Venezuela both in the park in India and in its surroundings, with deficiencies from the point of view of shelter, food, medical assistance, as well as unhygienic and unhealthy conditions. The methodology addressed in this research is emphasized in a qualitative approach, allowing an approximation of the real context through which the current situation of Venezuelan immigrant children in the Department of La Guajira will be known. It is used as data collection instruments; the observation guide (GO) and the semi-structured interview (ES). The study will determine the real conditions that Venezuelan immigrant children suffer in their daily lives, as well as designing and implementing actions that allow them to improve these conditions, as well as basic needs for shelter, food and health, from a humanistic and social approach.
\end{abstract}

Keyword - Immigrants, Design, Children, Action-Implementation, Humanist, socioeconomic

\section{INTRODUCTION}

The present investigation corresponds to the analysis of the socioeconomic situation of the immigrant children of Venezuela, between them and their environment. Currently, the number of Venezuelan immigrants has increased considerably due to the situation their nation is going through, and among these immigrant groups are a large number of children, which are vulnerable to the daily living situations of these people in the Department of La Guajira. This study was born from observation, which was made by managers, teachers and students of the University of La Guajira in partnership with specialists of the National Police, who were present in the Park of India, forming a research group with the purpose of developing the project. This study was born from observation, which was made by managers, teachers and students of the University of La Guajira in partnership with specialists of the National Police, who were present in the Park of India, forming a research group with the purpose of developing the project. Representing this situation in a micro-universe of what happens in different areas within the Department of La Guajira in general, these 'symptoms' characterize the reality of a population, especially the Venezuelan children in conditions of immigrant in an extreme state of unhealthiness, without any kind of shelter, adequate food, medical assistance, among others, which finally translates into inhumane conditions of life.

The problem, as explained below, is highly worrying from any point of view, especially within the social aspect, because it directly affects the most basic conditions of life of Venezuelan brothers and sisters, who have been fleeing from the current conditions of their country of origin, in search of better living conditions, which escapes a lot of reality in the face of the real situation they face in their day to day life.

Therefore, given this reality, it is considered very important to study the real situation of Venezuelan immigrants, especially children, with the purpose of implementing social action spaces to improve the current socioeconomic situation of children and Venezuelan immigrant girls in the Department of La Guajira. 


\section{THEORETICAL BASES}

According to the Dictionary of Social Sciences of the Institute of Political Studies, Migration naturally refers to population movements, relatively voluntary. Migrations can be internal or external, depending on whether they are carried out inside or outside the territory, respectively.

The glossary on Migration published by the International Organization for Migration (IOM) defines Migration as the "Movement of population into the territory of another State or within it, which encompasses all movement of persons, whatever their size, composition or Causes; includes migration of refugees, displaced persons, uprooted people or economic migrants" and as a Migrant "it usually covers all cases in which the decision to migrate is taken freely by the person concerned for reasons of personal convenience and without the intervention of external factors that force him to do so. Thus, this term applies to people and their relatives who go to another country or region with a view to improving their social and material conditions and their perspectives and those of their families".

\section{A. General considerations about migrations}

International migrations are multidimensional social phenomena, so polyhedral and multifaceted, so diverse in their composition, so volatile in their dynamics, so complex in their causes and effects in origin and destination, that they have ended up awakening the interest of diverse specialists, of diverse disciplines and different currents of theoretical interpretation [1].

When it comes to international migrations, we enter into a complex and confusing space. In this sense, among the edges that includes the study of migrations, emphasis should be placed on the behavior of the individual as well as the environment in which he is a part, without emanating it could be simply summarized in a premise: "improve the present life" [2].

\section{B. Motivation that justifies migrations}

Within the theories, which explain the justification of migrations, is the [3] which was considered the father of migrations and develops the "push-pull" theory, which provides 7 laws of which we will mention some:

- The main cause of migration is economic disparities and the economic motive predominates among the reasons for migration.

- Migrants who travel long distances generally go in preference to one of the major centers of commerce or industry.

- Migrations occur in stages.

- The dispersion process is inverse to the absorption process and exhibits similar characteristics.

- Each migratory current produces a compensating crosscurrent.

- The majority of migrants are adults.

This author is known for formulating a series of laws that allowed to begin to generate knowledge about the characteristics of the emigrants, allowing to demonstrate that "similar conditions produce similar migratory movements"; considered that the majority of more migrations is voluntary, so within the motives or stimuli to emigrate can speak of educational facilities, healthiness or high cost of living, in addition migrations according to the author is part of the process of economic, social and cultural, and as a preaching, it indicates in one of its 7 laws that there will be an increase in migrations: "I believe that an increase of the main means of locomotion and a development of manufactures and trade will lead to an increase in migration”.

For his part, [4] extends [3] from seven to twelve, including among the most outstanding: the main cause of migration is economic disparities and the economic motive predominates among the reasons for migrations; It also notes that: most immigrants are adults, large cities grow more by immigration than by vegetative increase and that migrations tend to increase with economic development and with the progress of technology and transport.

\section{Basic needs inherent in every person}

In this aspect, it is important to mention the theory about human motivation developed in 1943 by Abraham Maslow [5] that was later expanded. The author formulates a hierarchy of human needs and argues that by meeting the most basic needs located at the bottom of the pyramid, the highest needs and desires can develop.

The Maslow Pyramid, or hierarchy of human needs, is a psychological theory proposed by Abraham Maslow in his work: A Theory of Human Motivation of 1943 [5], which he subsequently expanded. Maslow formulates a hierarchy of human needs in his theory and argues that as basic needs are met (bottom of the pyramid), and human beings develop higher needs and desires (upper part of the pyramid). 
The scale of Maslow's needs is often described as a pyramid consisting of five levels: the first four levels can be grouped together as "deficit needs" (primordial); at the higher level, he called it "self-realization", "growth motivation", or "need to be". "The difference is that while the needs of deficits can be met, the need to be is a continuous driving force".

The basic idea of this hierarchy is that the higher needs occupy our attention only when the lower needs of the pyramid have been met. The forces of growth give rise to an upward movement in the hierarchy, while the regressive forces push the prepotent needs down into the hierarchy. According to the Maslow pyramid we would have:

1. Basic needs: They are basic physiological needs to maintain homeostasis (referring to health); within these, the most obvious are: Need to breathe, drink water, and feed; need to maintain the balance of $\mathrm{pH}$ and body temperature; the need to sleep, unwind and eliminate waste; need to avoid pain and have sex; security and protection needs.

These arise when the physiological needs remain compensated. There are the needs of feel safe and secure, even develop certain limits as to the order. Within them we find: Physical and health security; employment, income and resource security; moral, family and private property security; affiliation and affection needs.

They are related to the affective development of the individual, are the needs of: Association, participation and acceptance.

They are fulfilled through the functions of services and benefits that include sports, cultural and recreational activities. The human being by nature feels the need to relate, be part of a community, to be grouped in families, with friends or in social organizations. Among these are: friendship, companionship, affection and love. These are formed from the social scheme.

2. Esteem needs: Maslow described two types of esteem needs, one high and one low. High esteem concerns the need for self-respect, and includes feelings such as confidence, competence, mastery, achievement, independence and freedom. Low esteem concerns respect for other people: the need for attention, appreciation, recognition, reputation, status, dignity, fame, glory, and even dominance. The decline in these needs is reflected in low self-esteem and the inferiority complex. Satisfying this need supports the sense of life and appreciation as an individual and professional, who can calmly step up and move towards the need for self-realization. The need for self-esteem is the need for balance in the human being, given that it is the fundamental pillar for the individual to become the successful man he has always dreamed of, or in a man destined to failure, which he cannot achieve anything by his own means.

3. Self-realization or self-actualization: This last level is somewhat different and Maslow used several terms to name it: "growth motivation", "need to be" and "self-realization". It is the highest psychological need of the human being, it is at the top of the hierarchy, and it is through its satisfaction that there is a justification or valid meaning to life through the potential development of an activity. This is reached when all the previous levels have been reached and completed, or at least to a certain extent.

\section{Methodology}

From the point of view of the methodology of the investigation, it is framed in type of basic investigation of qualitative approach, of the hermeneutic-interpretative type, with a documentary design. Having as a unit of analysis reports from multilateral organizations, of recognized authors, the results will be elaborated through the perception of the real situation of Venezuelan immigrant children in the Department of La Guajira, being able to observe it from the micro universe and go basting the micro universes, until obtaining a broader panorama of the general conditions of life of the study group.

The data collection techniques that will be used will focus on investigating the current situation of Venezuelan immigrant children in the Department of La Guajira, their real daily living conditions from the most basic conditions for any human being, and with the purpose of developing and implementing actions to minimize or mitigate the reality of them.

\section{A. Data collection}

Regarding the process of obtaining and collecting the information, which was done through (Observation Guidelines, GO), applied to a population of more than 100 people between adults and children; and two (semistructured interviews, ES), applied to a population of 50 adults and another applied to a population of 20 children.

\section{B. Field work}

Fieldwork activities were developed corresponding to the dynamics of the research for the achievement of information. For this, daily life becomes a 'living' laboratory where all situations were susceptible to the collection of verbal information. All the spaces will be possible to find situations that refer to the research topic. Regarding the time dedicated to the collection of information, these were permanent in the aforementioned 
spaces for approximately six months. In these times and spaces, the tools proposed for the collection were applied.

\section{Instruments}

For this point two types of techniques will be used which are the observation guide, which, according to [6] "allows access to the cultural behavior of groups and record the actions of individuals in their daily activity". Another technique is the semi-structured interview (ES), which, according to [6] is "A conversation or face-toface verbal exchange, which aims to know in detail what a person thinks or feels about a particular issue or situation".

\section{RESUlts}

\section{A. Findings Found At The First Visits}

It is evident the needs of all kinds that this population suffers, consisting of pregnant women to adults, with children, who approach and express various complaints that are usually similar; on May 14, 2018, a research group made up of executives, teachers and students from the University of La Guajira, in partnership with specialists from the National Police, was present in the park of India, for the development of the present investigation that aims at diverse objectives, but especially to implement actions to improve the conditions of the quality of life of these people. The following situation is perceived:

- About one hundred immigrant people live in Venezuela, specifically children and many children in the park of India and in its surroundings.

- They suffer from: food, medical assistance, shelter, unhealthiness, among others.

- Employment alternatives: street vendors and car cleaners.

- Unsanitary conditions.

On the other hand, the population expresses more specific situations such as the case of a girl with Down syndrome, who had to be transferred to Barranquilla for medical assistance since in the District of Riohacha her mother could not get, constantly there are sick people who in most cases have high fevers, likewise they get "pieces" to spend the night at fifteen thousand pesos but they do not have the basic services (electricity, water and gas), they also feel outraged when the police try to get them out of the park and likewise when they seize their merchandise and these place resistance aggressively to avoid the dispossession of their only sustenance, As a consequence of which they get imprisoned, despite the aforementioned, some express that they feel at ease because of the humanitarian aid offered by the citizens of the Department of the Guajira of Colombia.

\section{FINAL CONSIDERATIONS}

The regulation of international migration is one of the central issues that refer to the movements of people, this has been seen by many governments as a threat to the unity and identity of its inhabitants and immigrants tend to be seen as marginalized minorities.

Going into the central theme of the study, this research aims to approach the current situation of Venezuelan immigrants in the Department of La Guajira, especially the situation of children, providing data for understanding and reflection of the current situation of the Venezuelan migratory phenomenon. The study seeks to know the real life perceptions of Venezuelan immigrant children in the territory of the Colombian Guajira, based on different dimensions, from which interesting findings will be obtained that ratify the new migratory reality of these groups. The analysis of the perceptions collected will show the situation of the daily life in which these children develop, which at first sight denote unhealthy and insecure conditions, widely deplorable within the Department of La Guajira, in their search for new opportunities, given the socioeconomic conditions that your country Venezuela is going through.

The Venezuelan migratory process presents a change of indisputable pattern. During the twentieth century, Venezuela consolidated itself as a receiving country for immigrants from Europe and Latin America, however, today the reality is that the Venezuelan population has become immigrants, consolidating a change in the migration pattern.

In this way, the present research presents as a general objective to implement social action spaces to improve the current socioeconomic situation of Venezuelan immigrant children in the Department of La Guajira that allow these siblings to enjoy at least the minimum conditions for the development of a "normal" life and possibilities for the future. 


\section{REFERENCES}

[1] M. Fernández, Aproximación interdisciplinar al análisis de las migraciones. Madrid: Universidad Pontificia Comillas, 2013.

[2] G. Malgesini and C. Gimenez, Guía de conceptos sobre Migraciones, racismo e intercultariedad. Madrid: Ediciones Los Libros de la Catarata, 2000.

[3] E.G. Ravenstein, “The Laws of Migration,” Journal of the Statistical Society of London, vol. 48, no. 2, pp. 167-235, 1885.

[4] J. Arango, "Las 'Leyes de las Migraciones' de E.G. Ravenstein, cien años después," Reis: Revista española de investigaciones sociológicas, no. 32, pp.7-26, 1985.

[5] A.H. Maslow, “Theory of Human Motivation”, Psychological Review, vol. 50, pp. 370-396, 1943.

[6] E. Bonilla-Castro and P. Rodríguez, Más allá del dilema de los métodos: la investigación en ciencias sociales, 3rd edition. Bogotá, Colombia: Grupo Norma Editorial, 2005.

\section{AUTHOR PROFILE}

Emérita Sofía Muñoz Estrada works as part-time professor in the University of La Guajira (Colombia). Mrs. Muñoz completed his magister from University of Cordoba (Colombia). Mrs. Muñoz completed his undergraduate in Bachelor in preschool at the University Antonio Nariño University.

Mirian Muñoz Estrada works as part-time professor in the University of La Guajira (Colombia). Mrs. Muñoz completed his magister from University of La Guajira (Colombia). Mrs. Muñoz completed his undergraduate in Environment Engineering at the University of La Guajira.

Katy Herrera works as part-time professor in the University of La Guajira (Colombia). Mrs. Herrera completed his magister from University of La Guajira (Colombia). Mrs. Herrera completed his undergraduate in Systems Engineering at the Autonomous University of the Caribbean.

Lina Meza-Andrade works as part-time professor in the University of La Guajira (Colombia). Mrs. MezaAndrade completed his magister from University of La Guajira (Colombia). Mrs. Meza-Andrade completed his undergraduate in Systems Engineering at the Autonomous University of the Caribbean.

Javier Pinedo works as full-time professor at the University of Cartagena (Colombia). Mr. Pinedo completed his magister from UNINI (Puerto Rico). 